\title{
El activismo político de la Iglesia católica durante el gobierno de Zapatero (2004-2010)*
}

\author{
Susana Aguilar Fernández \\ Universidad Complutense de Madrid. Departamento de Sociología I \\ saguilar@cps.ucm.es \\ Susana@ceacs.march.es
}

Recibido: 03-05-2010

Aceptado: 15-06-2010

\section{Resumen}

Este trabajo analiza la Iglesia católica española (ICE) como un grupo de interés que persigue mantener y/o aumentar su influencia política mediante la adopción de decisiones racionalmente calculadas que afectan a su statu quo y a sus objetivos declarados. El perfil político de las iglesias puede, sin embargo, ser bajo o alto. El segundo se plasma generalmente en estrategias de adversario político, como la escogida por la ICE para oponerse a dos reformas políticas del gobierno socialista de Zapatero: la del matrimonio para personas del mismo sexo y la de ampliación del aborto. Mientras que otras iglesias católicas en distintos países europeos se han abstenido de ejercer un protagonismo político similar, la ICE se ha implicado con gran intensidad en esta lucha política a través del desarrollo de campañas y la movilización social. Las teorías de la oferta del mercado religioso (basadas en la rational choice), que ponen el énfasis en la importancia de los distintos tipos de iglesia y de liderazgo religioso existentes en diversos países, pueden explicar el activismo político de inspiración religiosa en España. La ICE no solo cuenta con importantísimos recursos de todo tipo, sino que, además, opera en un mercado religioso cuasi monopolista que facilita su discurso como «la institución que representa a la gran mayoría de los españoles». Por otro lado, la aprobación de «políticas altamente sensibles» de contenido ético ha coaligado a determinados sectores sociales y partidos políticos opuestos a las mismas. Para defender los objetivos pro familia y pro vida, la ICE ha escogido una estrategia conflictiva que abarca desde la presión política y el lobby, la organización de conferencias de prensa y la publicación de comunicados, hasta el apoyo ( $y$, en ocasiones, promoción directa) a manifestaciones organizadas primordialmente por grupos sociales de inspiración cristiana y, subsidiariamente, por partidos políticos de corte conservador.

Palabras clave: grupo de interés, adversario político, Iglesia católica, políticas socialistas.

* Este artículo se inserta dentro del proyecto titulado, Religiosidad, ideología y voto en Europa (SEJ2006-10073/CPOL), financiado por el Ministerio de Ciencia e Innovación, y dirigido por el prof. José Ramón Montero. Agradezco la muy útil información proporcionada sobre la Conferencia Episcopal por parte de uno de los revisores anónimos de Papers. 
Abstract. The political activism of the Spanish Catholic church under the Zapatero Government (2004-2010)

This article analyzes the Spanish Catholic church (SCC) as an interest group which pursues to maintain and/or enhance its political influence through the adoption of rationally-calculated decisions that will impinge upon its status quo and objectives. However churches can exhibit a high or a low political profile, the former generally adopting the shape of a political adversary strategy. This role has been chosen by the SCC in order to oppose two political reforms advocated by the Socialist government of Zapatero: same-sex marriage and the liberalization of abortion. Unlike other Catholic churches in different European countries which have refrained themselves from entering politics, the SCC has decisively involved itself in this political fight by means of campaigns and social mobilization against these reforms. Supply-based and rational choice theories, which emphasize the importance of different types of existing church and religious leadership in various countries account for this religiously-inspired political activism in Spain: the SCC not only counts on important resources but it also operates in a quasi-monopolist religious market that paves the way for its discourse as «the institution which represents the great majority of Spaniards». Further, the passing of these "highly sensitive policies» has united certain social sectors and political parties which do not approve them. In the quest to defend pro-family and pro-life objectives, the SCC has opted for a conflictive strategy which goes from political pressure and lobbying, press conferences and the publication of documents, to the support (and direct promotion at times) of demonstrations, primarily organized by Christian social groups and, less visibly, conservative political parties.

Key words: interest group, political adversary, Catholic church, socialist policies.

\begin{tabular}{|c|c|}
\hline \multicolumn{2}{|c|}{ Sumario } \\
\hline 1. Introducción & 4. Las alianzas de la Iglesia católica \\
\hline 2. La Iglesia católica española & en tiempos de crisis \\
\hline $\begin{array}{r}\text { como grupo de interés y las políticas } \\
\text { altamente sensibles }\end{array}$ & $\begin{array}{l}\text { 5. Estrategias de movilización contra } \\
\text { las políticas altamente sensibles }\end{array}$ \\
\hline 3. La estructura organizativa & 6. Conclusiones \\
\hline $\begin{array}{r}\text { y los recursos de la Iglesia católica } \\
\text { española }\end{array}$ & Referencias bibliográficas \\
\hline
\end{tabular}

\section{Introducción}

Algunos autores afirman que ciertas religiones han adquirido un visible perfil político a partir de la década de 1980 (Casanova, 1994). El caso del catolicismo en España desde comienzos de la democracia y principalmente a lo largo de los dos distintos períodos de gobierno socialista, primero bajo la presidencia de González (1982-1996), y posteriormente bajo la de Rodríguez Zapatero (2004-), parece confirmar esta idea. Más concretamente, la Iglesia católica española, como institución que preserva oficialmente el catolicismo en el país, se ha convertido (en alianza con otras fuerzas sociales y políticas) en un des- 
tacado adversario político del Gobierno desde el año 2004'. En el desempeño de este papel, la ICE no se ha limitado a difundir ideas críticas con respecto a determinadas actuaciones del gobierno, tal y como otras iglesias han hecho en distintos países, sino que su papel se ha centrado primordialmente en invertir importantes recursos de distinto tipo con el objetivo de desarrollar campañas y contribuir a movilizar a distintos sectores de la sociedad contra políticas que considera «altamente sensibles». La hipótesis del artículo es, por lo tanto, que la religión en las sociedades secularizadas puede dejar de ser un asunto principalmente privado (aunque nunca haya sido ni vaya a ser privado de forma exclusiva) si existen instituciones religiosas, o elites eclesiásticas, que deciden desempeñar un papel político y apoyar determinadas campañas públicas, al tiempo que ayudan con éxito a la movilización de ciertos grupos sociales y partidos políticos que comparten sus objetivos. Obviamente, las causas por las cuales determinadas iglesias deciden elegir esta opción mientras que otras se abstienen de entrar en la arena política será uno de los principales temas a analizar. Aunque existan razones exógenas que puedan explicar el activismo político, se argumentará que son más relevantes las de tipo endógeno relativas a la ICE, en particular su específica situación dentro de la sociedad española y la peculiar relación entre la Iglesia y el Estado existente en el país: el cuasi monopolio del catolicismo en el mercado religioso y los enormes recursos de la ICE, así como la privilegiada posición de la Iglesia dentro del aconfesional Estado español, ayudan a entender este activismo ${ }^{2}$.

El artículo se estructurará de la siguiente forma: la primera parte define la ICE como grupo de interés e identifica dos políticas promovidas por el gobierno de Zapatero contra las que la Iglesia se ha movilizado (lo que aquí se denomina "políticas altamente sensibles» (PAS), referidas a las reformas que han dado lugar al «matrimonio homosexual» y a la ampliación del aborto); las especificidades de la Iglesia como grupo de interés y como actor dentro de la socie-

1. Aunque en España el conflicto público entre actores eclesiásticos y políticos haya coincidido principalmente con gobiernos socialistas, la tensión ha sido mayor bajo la presidencia de Zapatero. La razón de ello es que el nuevo liderazgo del PSOE se ha desviado de las tradicionales prioridades socialdemócratas, centradas, entre otros temas, en el empleo y la solidaridad, y se ha volcado en mayor medida en ampliar libertades y derechos civiles, en línea con las ideas de republicanismo civil del filósofo Philippe Pettit (Calvo, 2009). A pesar de que existe una cierta proximidad ideológica entre la ICE y el PP, ambos han defendido ideas distintas en una serie de temas: el gobierno de Aznar (1996-2004), por ejemplo, no revocó la Ley de despenalización del aborto aprobada bajo la presidencia de González en 1985, mientras que su más dura postura en políticas de inmigración ha sido criticada por ciertas figuras dentro de la Iglesia (por no mencionar los importantes desacuerdos relacionados con el apoyo del PP a la administración Bush durante la guerra de Irak).

2. El enorme peso de la Iglesia en la historia española y su papel fundamental en la construcción del estado-nación son, obviamente, factores a tener en cuenta. De hecho, la existencia de países con ideologías de secularismo asertivo (Francia y Turquía, por ejemplo) y secularismo pasivo (EEUU) respondería a las condiciones históricas concretas que rodearon el proceso de formación de sus estados y a las específicas relaciones entre la Iglesia y el estado (Kuru, 2007). 
dad civil son también objeto de estudio en esta sección. La segunda parte del artículo ayuda a ubicar el trabajo dentro de las teorías que, poniendo el énfasis en la oferta, se conocen como teorías del mercado religioso (o de la elección racional) y de la movilización de recursos. En línea con esta última teoría, la tercera parte presenta a la Iglesia como una institución que, contando con importantes recursos de distinto tipo, ha decidido desempeñar un activo papel político, porque percibe, entre otras razones, que puede desempeñarlo con ciertas garantías de éxito. Bajo qué circunstancias decide la ICE movilizar la religión con fines políticos es analizado en la cuarta parte, que también se centra en el tipo de relación que la ICE ha establecido principalmente con determinados grupos sociales cristianos (alianzas sociales) y, en menor medida, partidos políticos (alianzas políticas). Finalmente, se discuten las estrategias de movilización en contra de las PAS que los aliados sociales (como protagonistas) y políticos (subsidiariamente) de la ICE han puesto en práctica.

\section{La Iglesia católica española como grupo de interés y las políticas altamente sensibles}

Los grupos de interés han sido definidos «como organizaciones que no son parte del gobierno sobre el que están intentando influir» y "como los representantes de subgrupos específicos en la sociedad que se vinculan a partidos políticos para así ser representados en el proceso político" (Berry, 1997: 4-5; Warner, 2000: 18). En este sentido, la ICE constituye un grupo de interés porque persigue mantener (cuando no aumentar) su influencia política en democracia mediante la adopción de decisiones racionalmente calculadas que afectarán, exitosamente o no, a su statu quo y a sus objetivos declarados. Al intentar conseguir determinados objetivos en un contexto democrático y pluralista, la ICE se ve «obligada» a forjar alianzas con determinados grupos sociales y partidos, al mismo tiempo que se ve enfrentada a otros. Anteriormente, ha habido autores que también han considerado la ICE como grupo de presión, aunque, paradójicamente, le hayan atribuido capacidades políticas dispares (demasiada/muy poca influencia o poder) (Requena, 2005: 335; Gurrutxaga, 2008: 67; Pérez-Agote, 2008: 126). La principal razón de esta discrepancia estriba en que el análisis empírico de la ICE como grupo de interés está todavía en estado embrionario y, por ello, este trabajo aspira a contribuir a estudiar un importante tema que ha sido escasamente analizado dentro de la ciencias sociales. El presente análisis no constituye, pues, un estudio de sociología de la religión (aunque utilice material que proviene de tal disciplina), sino que se ubica claramente dentro del campo de la sociología política.

Puesto que la ICE es vista como un grupo de interés que toma decisiones que afectan a su statu quo y a sus objetivos públicamente declarados, se analizarán estas decisiones en relación con dos asuntos que conforman lo que se ha denominado las PAS. La ICE percibe en estas políticas la necesidad indiscutible de «retar la absoluta autonomía legal de las esferas seculares y sus pretensiones a organizarse [...] sin tomar en cuenta consideraciones morales o éti- 
cas externas» (Casanova, 1994: 57-8). Estas políticas se ven acompañadas de altas intensidades de preferencias por parte de grupos sociales (y, en menor medida, partidos) de inspiración cristiana. Los dos objetivos a analizar son:

- La defensa de un modelo de familia en el que una mujer y un hombre se comprometen, a través de la sagrada institución del matrimonio, a mantener una relación a lo largo de sus vidas y, en su caso, a educar a sus vástagos de forma cristiana con una intromisión mínima del Estado.

- La defensa de la vida, desde el primer momento de existencia del embrión hasta el último hálito de la persona.

El primer objetivo ha enfrentado a la ICE con el gobierno de Zapatero debido a la modificación que éste promovió del Código Civil para permitir el matrimonio entre personas del mismo sexo en junio del 2005 (el denominado divorcio express, que facilita el proceso de separación y que fue aprobado un mes después, tampoco fue del agrado de la Iglesia). El segundo objetivo ha provocado una importante tensión política debido a la reforma del aborto - la Ley de salud sexual y reproductiva e interrupción voluntaria del embarazo- - aprobada en diciembre del $2009^{3}$ (la Ley de reproducción asistida del 2006 también fue criticada, aunque no con la misma vehemencia, por la ICE).

\subsection{Las peculiaridades de la Iglesia como grupo de interés}

Aunque las iglesias católicas (IC) se comportan generalmente como grupos de interés y no como instituciones públicas (Minkenberg, 2003), lo hacen indudablemente de una forma muy peculiar: las IC «afirman que sus principios son universalmente aplicables» y se consideran «la autoridad moral última». Debido a su históricamente prolongada y profunda implicación en la política europea, exhiben una extrema «sensibilidad hacia lo que perciben como afrentas a sus prerrogativas»; "muchas de las exigencias de la Iglesia no son negociables» y "luchan por mantener el control sobre un aspecto de las personas que la mayoría de los grupos de interés han cedido al Estado o al ámbito de la autonomía individual: los valores [y] la moral». Todo ello implica que la relación de las IC con "los sistemas políticos democráticos y seculares haya sido problemática» (Warner, 2000: 7-8). Según Casanova, «las instituciones y organizaciones religiosas se niegan a limitarse al cuidado pastoral de las almas y siguen cuestionando las interconexiones entre la moral privada y la pública, al tiempo que plantean retos a los subsistemas, particularmente los estados y los mercados, que pretenden estar exentos de consideraciones normativas externas» (1994: 5).

Junto a estas peculiaridades, hay que tener en cuenta, además, que la ICE no puede ser considerada de forma inequívoca parte de la sociedad civil si se entien-

3. La primera legislación sobre el aborto, la Ley de despenalización (parcial) del aborto, aprobada en julio de 1985, también provocó importantes fricciones entre el Gobierno de González y la Iglesia. 
de este concepto como la suma de asociaciones voluntarias que intentan ofrecer límites al poder y la «arbitrariedad» del Estado. La razón de ello es que la ICE no es, en sentido estricto, una asociación voluntaria: en la mayoría de los casos, la pertenencia a la Iglesia no es el resultado de una decisión individual, sino familiar, que se plasma en el bautismo en la infancia. Por otro lado, la Iglesia no facilita los mecanismos de salida y voz (exit y voice), aplicados por Hirshman a las «organizaciones [...] que proporcionan servicios a sus miembros sin una contraprestación monetaria directa» (1970: 3): la ICE pone todo tipo de dificultades a los individuos que deciden dejar de ser católicos y desincentiva severamente el debate abierto y el disenso dentro de sus filas (evidentemente, este último punto no se aplica únicamente a la Iglesia, sino también a otros grupos dentro de la sociedad civil de tipo jerárquico-vertical, como partidos y sindicatos). Asimismo, la ICE no entiende la democracia como un mecanismo político de negociación y trade-offs en el que las reglas del juego están claramente definidas y son aceptadas por todas las partes en conflicto, sino que tiende a percibir el proceso político como un juego de suma cero en el que ganadores y perdedores pueden ser inequívocamente identificados. Se podría explicar esta percepción por la postura no acomodaticia de la Iglesia en relación con la defensa de algunos de sus más importantes objetivos, los cuales no son solo definidos como principios morales absolutos (legislar contra los mismos constituye un ataque al derecho natural), sino que, además, tienen una naturaleza indivisible (no se ajustan a la lógica de las políticas redistributivas). Estos objetivos son los que conforman las PAS: el objetivo pro familia (como rechazo total al matrimonio que no sea entre hombre y mujer) y el pro vida (como rechazo total a cualquier tipo de interrupción «no natural» de la gestación). Por último, la percepción de la democracia como juego de suma cero puede estar más enraizada en la ICE debido a su corta experiencia democrática (en términos comparativos) y a su presencia hegemónica dentro de la sociedad.

La transformación copernicana de la ICE, que la ha convertido en una iglesia centrada en la sociedad (society-centred) en un contexto no confesional (disestablished), cuando históricamente ha sido una iglesia centrada en el estado (state-centred) en un contexto confesional (established), se inicia a finales de la década de $1970^{4}$. De forma parecida a como «el Vaticano se vio a sí mismo situado en el centro del universo católico» en Italia tras la Segunda Guerra Mundial (Warner, 2000: 9), la ICE se ha percibido históricamente como el guardián de la ortodoxia católica en España. Tras casi cuarenta años de armoniosa convivencia con la dictadura franquista, etapa en la que los asuntos religiosos y los de estado estaban inextricablemente entrelazados (de manera que el nacional-catolicismo fue la enseña del régimen hasta finales de los años cincuenta), ciertos sectores de la Iglesia comenzaron a distanciarse del franquismo durante los años sesenta, hasta que estalló el conflicto entre ambos ya en la

4. Para una descripción sucinta de la ICE en la historia de España, véanse Casanova (1994: 75-81), Pérez-Agote (2008: 87-118) y Anderson (2003: 139-40) 
siguiente década. A partir de 1976, el nuevo estado democrático y aconfesional intentó cerrar una oscura etapa en la historia del país, al mismo tiempo que buscaba preservar el estatus privilegiado de la ICE bajo nuevas circunstancias políticas.

El rechazo de la ICE a un contexto de total e inequívoca no confesionalidad parece haber encontrado acomodo en la Constitución (art. 16) ${ }^{5}$, según la cual España es un estado aconfesional («ninguna confesión tendrá carácter estatal», art. 16.3). Este término intenta establecer una situación a medio camino entre los países laicos (como Francia, Bélgica y los Países Bajos) y los confesionales de distinto tipo (Alemania es oficialmente biconfesional, el anglicanismo es la Iglesia de estado en Inglaterra y los países nórdicos tienen iglesias nacionales protestantes). Asimismo, el aconfesionalismo aspira a superar en España el vívido contraste entre el Estado laico de la Segunda República y el Estado confesional franquista. Durante la etapa de debate constitucional, por otro lado, la Iglesia dejó clara su «oposición al estilo americano de separación entre la Iglesia y el estado" (Anderson, 2003: 140). Aunque el Tribunal Constitucional ha utilizado a menudo el término laicismo positivo para referirse a la situación religiosa en España, el Estado español no es laico, porque la ICE disfruta de un estatus privilegiado. En términos de libertad religiosa, por ejemplo, la Constitución reconoce implícitamente el hecho sociológico de que la mayoría de los españoles son católicos («los poderes públicos tendrán en cuenta las creencias religiosas de la sociedad española») y obliga a los poderes públicos a que mantengan «las consiguientes relaciones de cooperación con la Iglesia católica y las demás confesiones» (art. 16.3). Además, la separación entre la Iglesia y el Estado no se entiende como neutralidad religiosa del Estado, ya que los acuerdos entre el Estado español y la Santa Sede de 1979 recogen, entre otras cosas, que la ICE no se ve afectada por la legislación en materia de asociaciones, que el matrimonio religioso tendrá validez civil y que se garantizará la asistencia religiosa en hospitales y cárceles. Finalmente, el artículo 27.3 de la Constitución señala: «los poderes públicos garantizan el derecho que asiste a los padres para que sus hijos reciban la formación religiosa y moral que esté de acuerdo con sus propias convicciones».

\subsection{Las teorias de la oferta o la importancia de los activadores religiosos}

De forma parecida a como la teoría de los cleavages se ocupa únicamente de aquellos cleavages sociales que entrañan consecuencias políticas identificables (Lipset y Rokkan, 1967), este trabajo no va a tratar del catolicismo en España como cleavage religioso latente. Sí se centrará, sin embargo, en la religión como cleavage manifiesto o, más concretamente, en la ICE como grupo de interés

5. El análisis de la Constitución se basa principalmente en Llamazares (2008) y también en Anderson (2003). Es interesante recordar que, según el Tribunal Constitucional, «los criterios o los intereses religiosos no pueden ser utilizados para medir la justicia o injusticia de las decisiones que emanan de los poderes públicos» (Llamazares, 2008: 155). 
que puede decidir o no, bajo determinadas circunstancias, activar políticamente la religión y, durante el proceso de activación, convencer con éxito a otros actores de la sociedad civil acerca de la necesidad de actuar contra determinadas políticas promovidas por el Gobierno. La transformación de un cleavage religioso latente en uno manifiesto con consecuencias políticas se hace visible a través de la opción (estrategias de movilización) adoptada por el activador del cleavage (la ICE y sus aliados) y de los resultados tangibles de tal opción (creación de un clima de enfrentamiento político).

El trabajo se centra, pues, en la oferta (el ofertante es la ICE) y no en la demanda (los católicos pueden reaccionar o no al ofertante). Las teorías basadas en la oferta han sido propuestas por analistas de la religión que trabajan dentro de las aproximaciones de la elección racional y la movilización de recursos. Ambas aceptan que «la demanda pública de religión [...] es constante» y aspiran a «rectificar el olvido en el que ha caído el lado de la oferta en los análisis sociológicos de la religión [a través] de dirigir la atención hacia el trabajo que desarrollan los líderes y activistas religiosos en cuanto a la movilización de recursos». En la línea de este argumento, los racionalistas afirman que la libre competencia en los mercados religiosos es altamente deseable, porque "las empresas religiosas buscan maximizar sus beneficios aumentando sus miembros y otros recursos materiales; si no existe regulación pública o subsidios estatales - los cuales distorsionan el mercado-, el éxito de las empresas religiosas dependerá de su habilidad a la hora de satisfacer a sus clientes». El escenario opuesto, caracterizado por "condiciones de monopolio u oligopolio, generalmente con subsidios estatales y barreras a la entrada [de nuevas empresas religiosas], favorece que las instituciones religiosas se vuelvan holgazanas y carezcan de los incentivos necesarios para proporcionar sus servicios de forma eficaz» (en Norris y Inglehart, 2004: 11; en Aldridge, 2000: 101, 103-4).

Aunque la tesis principal de las teorías basadas en la oferta (según la cual los ofertantes religiosos son importantes y pueden, bajo determinadas circunstancias, ser el factor que explique la diferente relevancia — salience - política de la religión en distintos países) va a servir de guía del presente trabajo, es necesario destacar dos importantes desacuerdos con estos estudios:

- En primer lugar, no se puede considerar la religión como un producto de mercado, porque ésta «no es, para la mayoría de la gente, una preferencia sino una identidad social heredada [...] que puede ser cambiada solo tras asumirse un alto coste personal $\aleph^{6}$ (Esteban, 2008: 301).

- En segundo lugar, no se puede explicar el diferente grado de religiosidad en Europa y en los Estados Unidos a través del pluralismo que caracteriza al mercado religioso norteamericano.

6. La excepción a la regla es la sociedad americana, en la cual un $40 \%$ de los individuos ha cambiado alguna vez de iglesia o de credo religioso. Bruce afirma que la alta «volatilidad religiosa» en el país puede ser explicada por la existencia de un mercado plural que etiqueta las religiones de forma superficial y consumista (Esteban, 2008: 300-2). 
El segundo argumento es especialmente relevante, porque la ICE opera en un mercado cuasi monopolista con generosos subsidios estatales y, sin embargo, no muestra el tipo de "apatía política» (u holgazanería, tal y como dirían los racionalistas) que frecuentemente se adscribe a las iglesias (nacionales) protestantes en contextos parecidos de mercado religioso. Más bien podría argumentarse, al contrario, que la identidad religiosa (y también la participación religiosa) puede ser más intensa en mercados monopolistas (Polonia, Irlanda, Italia, Grecia, etc.) que en mercados pluralistas y que, bajo determinadas circunstancias (en tiempos de crisis), esta identidad puede ser movilizada y convertida en acción política más fácilmente en mercados no competitivos (España) que en mercados competitivos ${ }^{7}$. Por supuesto, la acción política de inspiración religiosa en España (y en otros países) es obviamente distinta de la innegablemente más alta participación en organizaciones religiosas de base que encontramos en Estados Unidos.

Si la oferta es entonces relevante, ¿qué sucede con la demanda? La demanda en muchos países europeos secularizados sigue siendo asombrosamente estable, en el sentido que la mayoría de los ciudadanos todavía se definen como cristianos de distinto tipo. La autodefinición religiosa no va, sin embargo, acompañada de la práctica religiosa, la cual se ha reducido prácticamente en todas partes: "creer sin pertenecer (believing without belonging) es una forma adecuada de caracterizar la persistencia de lo sagrado a pesar del declive de la asistencia a los oficios" (Davie, en Aldridge, 2000: 3). Si la demanda es estable (autodefinición), o ha descendido (práctica), ¿cómo puede explicarse que la religión sea activada políticamente en determinados países pero no en otros? Tal y como se dijo previamente, la respuesta estriba en la oferta: es la oferta la que fluctúa o, más en concreto, lo que importa es el tipo de iglesia que opera en distintos contextos. El tipo de iglesia y de líderes religiosos es, por lo tanto, un asunto crucial a analizar.

De forma simplificada, se puede afirmar que las iglesias y el liderazgo religioso en Europa oscilan entre las «apolíticas» iglesias protestantes nacionales dentro de estados confesionales y las "políticas» iglesias católicas supranacionales dentro de estados no confesionales ${ }^{8}$. Las IC pueden disfrutar de una situación de cuasi monopolio en el mercado religioso (España, Italia, Irlanda, Polonia, etc.) o coexistir con otras confesiones importantes (Países Bajos, Bélgica, Alemania, etc.). Según la teoría de los cleavages (Lipset y Rokkan, 1967), las IC no pueden ser consideradas históricamente como iglesias nacionales debido a su lealtad a un poder «supranacional»: el del Papa en el estado Vaticano. Este hecho se tradujo en un tipo de iglesia que se opuso a la centra-

7. Por ello, las teorías basadas en la oferta tienen «problemas a la hora de explicar la prolongada fuerza de las congregaciones en muchos países del sur de Europa, a pesar del papel monopolístico de las IC» (Norris e Inglehart, 2004: 13).

8. Para una visión comparada de las iglesias en distintos estados europeos, véase el monográfico de West European Politics, Church and State in Contemporary Europe (enero, 1, 2003). 
lización política y a la unificación nacional que defendieron principalmente las fuerzas liberales anticlericales en el siglo XIX. El choque entre los liberales y las IC no impidió que los líderes eclesiásticos cambiaran de aliado cuando, durante el primer tercio del siglo XX, los partidos socialistas y comunistas en auge comenzaron a representar en ciertos países un reto mucho más serio que el de los liberales para el poder de la Iglesia: la nueva «amistad» entre los liberales y la Iglesia encuentra su mejor ejemplo en el Pacto Gentiloni suscrito en Italia en 1913 (Warner, 2000: 49). Actualmente, la etapa de «organicismo reactivo», entendido éste como la respuesta defensiva y centrada en el estado de las IC ante las formaciones anticlericales, ha tocado a su fin. Aunque este «organicismo» adoptó distintas formas en distintos países, una de sus manifestaciones más significativas fue el apadrinamiento por parte de las IC de partidos católicos. Como consecuencia de factores tales como el Concilio Vaticano Segundo, las IC comenzaron gradualmente a desterrar sus visiones suspicaces hacia el juego político democrático y plural a partir de la década de 1960. «El desarrollo más significativo que aparece en las recientes transiciones a la democracia ocurridas en países católicos es el hecho que [...] en todos los lugares las IC han aceptado no solamente la separación constitucional iglesia estado y el principio de libertad religiosa, sino que también han abandonado sus esfuerzos tradicionales por establecer o apoyar partidos católicos oficiales» (Casanova, 1994: 62).

A pesar de que ésta ha sido la tendencia general, no todas las IC ni todos los electorados predominantemente católicos han seguido la misma pauta en distintos lugares. Es necesario, entonces, realizar un análisis histórico que ayude a explicar las diferentes estrategias de las iglesias, así como los distintos comportamientos de los creyentes en distintos países y períodos ${ }^{9}$. El crucial papel desempeñado por la IC en la historia de España y su enorme acumulación de recursos a lo largo del tiempo, la enraizada homogeneidad religiosa de la sociedad española, la sin parangón presencia de la ICE durante la longeva dictadura franquista, así como su gradual distanciamiento del régimen desde finales de la década de 1960, pueden haber contribuido al desempeño de un papel político activo por parte de la Iglesia en democracia. Aunque la Iglesia no ha apadrinado oficialmente ningún partido, nunca se ha abstenido de transmitir recomendaciones políticas al electorado católico. Cuando los gobiernos mostraban una actitud conciliadora y acomodaticia en relación con el statu quo de la ICE, tal y como ocurrió durante las fases iniciales de transición a la democracia, la Iglesia adoptaba un perfil político bajo. La opción por un perfil político alto, que se traduce generalmente en activismo político adverso, ha tenido lugar siempre que la Iglesia ha percibido, en coyunturas concretas, que sus intereses vitales estaban siendo atacados por determinados gobiernos. Ciertos

9. «Las distintas IC nacionales han mostrado históricamente diferencias claras y fundamentales [...] al menos desde la aparición del estado moderno, el carácter público de cualquier religión está determinado primordialmente por la particular ubicación estructural de la religión entre el estado y la sociedad» (Casanova, 1994: 9). 
factores exógenos también pueden ayudar a entender esta estrategia: desde la celebración del Concilio Vaticano Segundo, las IC iniciaron un complicado proceso de aceptación de las democracias pluralistas que fue compatible (sin embargo) con la existencia de «un alto perfil público en el mundo» (Casanova, 1994: 9). Este perfil se ha visto reforzado por los papados de Juan Pablo II y, actualmente, de Benedicto XVI.

\section{La estructura organizativa y los recursos de la Iglesia católica española}

La opción por un determinado tipo de actuación por parte de un grupo de interés se relaciona con factores endógenos y exógenos. Las oportunidades políticas, o la percepción de que existe un contexto político favorable, constituyen el factor exógeno por excelencia. La disponibilidad (o ausencia) de recursos, como factor endógeno que condiciona la puesta en práctica o no de acción colectiva, ha sido recogido por la teoría de la movilización de recursos: de forma breve, si un grupo de interés se considera lo suficientemente fuerte como para ejercer su influencia con un cierto grado de éxito en la esfera pública, podrá decidir racionalmente movilizar sus recursos con independencia del específico contexto político existente. Este es el escenario en el que se analizará la ICE.

Desde una perspectiva organizativa, el principal actor dentro de la ICE es la Conferencia Episcopal Española (CEE), que, creada en 1966, sigue las directrices del documento, Christus Dominus, aprobado por el Concilio Vaticano Segundo, el cual «ordena el establecimiento de conferencias episcopales nacionales y regionales» (Casanova, 1994: 73). Además, la CEE tiene personalidad jurídica civil (art. 1.3), tal y como recoge el Acuerdo de 1979 entre el Estado español y el Vaticano ${ }^{10}$. La CEE conforma una «institución permanente integrada por los obispos españoles que, de común acuerdo con el Papa, llevan a cabo conjuntamente las funciones pastorales del Episcopado Español» (Estatutos, art. 1.1). Como actor, la CEE mantiene una continua relación con el representante oficial del Vaticano en España (la Nunciatura Apostólica) y se ha convertido en el portavoz oficial de la ICE con el Estado. La ICE se ha transformado en un grupo de interés moderno a través de la estructura coordinada y formal de la CEE: «con anterioridad, la jerarquía eclesiástica constituía una masa (relativamente) amorfa — desorganizada, no-institucionalizada - y controlada desde fuera» (Pérez-Agote, 2008: 88, 124). El actor colegiado que es la CEE no anula, sin embargo, la autoridad de los obispos en sus respectivas diócesis (en número de 67), ni puede imponer a las congregaciones religiosas sus puntos de vista. Los comunicados de la CEE deben ser, por lo tanto, negociados internamente y, según sea el presidente de la misma, las líneas argumentativas pueden ser definidas como acomodaticias (Blázquez) y no acomodaticias $(\text { Rouco })^{11}$. La estructura organizativa de la CEE es la siguiente (cuadro 1).

10. www.laicitat.org/.../AcuerdoEstadoySantaSedesobreasuntosjuridicos_1979

11. Prueba de disenso es que la mayoría de la jerarquía eclesiástica apoyó el sí a la Constitución, pero nueve obispos animaron a sus feligreses a que rechazaran el texto. Un ejemplo más 


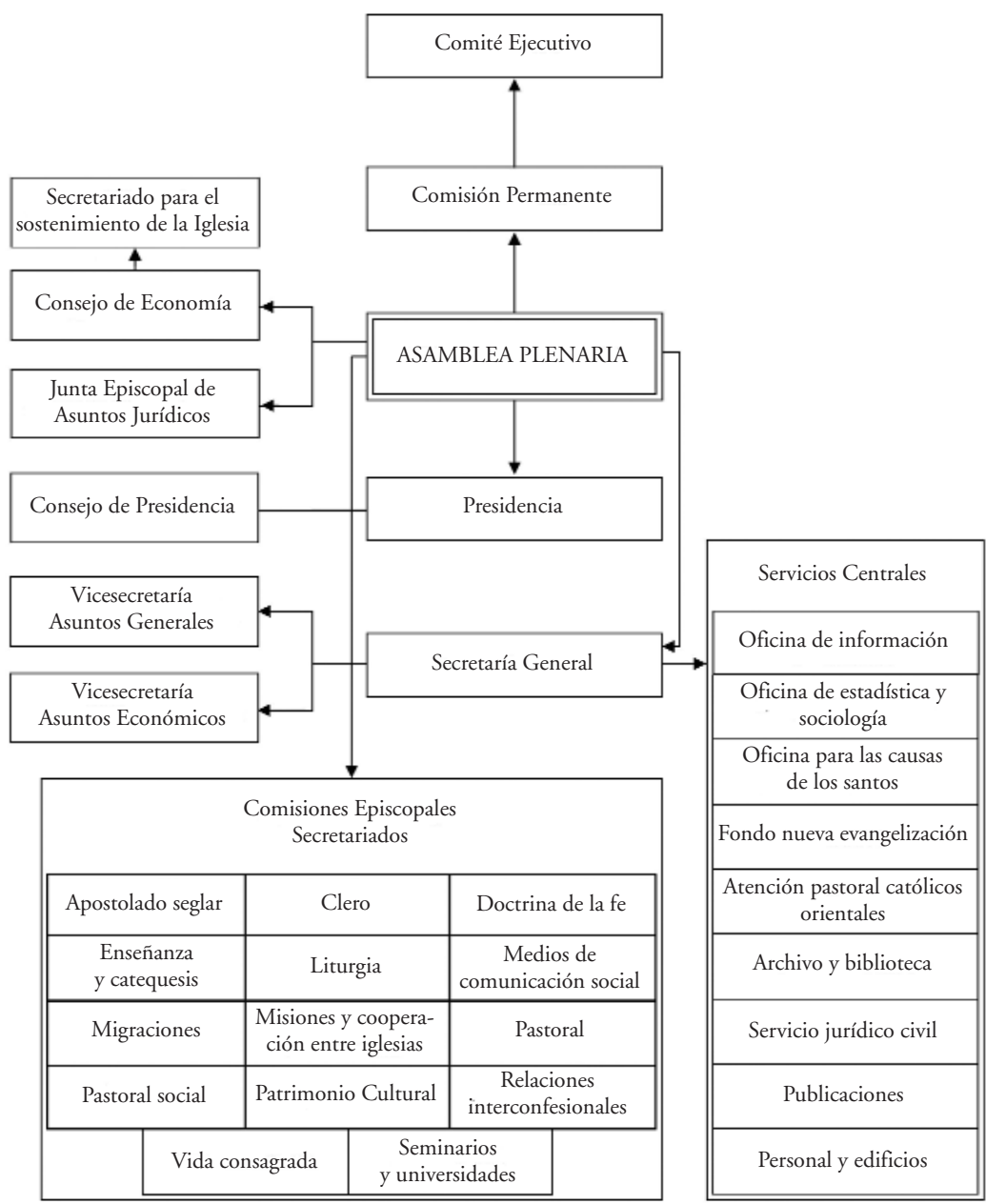

Cuadro 1. Estructura organizativa de la CEE

reciente de las dificultades de la CEE a la hora de "convencer» al mundo católico de su visión es el de la asignatura educación para la ciudadanía, denostada por los obispos como una ilegítima intromisión del Estado en el derecho de los padres a elegir la educación moral de sus hijos, mientras que la Federación Española de Religiosos de Enseñanza (FERE), que agrupa a los titulares de los centros educativos católicos, ha aminorado la controversia y ha preparado sus propios libros de texto en muchos casos. Además, «muchas de las obras católicas en educación y sanidad tienen convenios con los órganos del Estado y/o las Autonomías, lo que dificulta su lealtad a los obispos». Agradezco este último punto a uno de los revisores anónimos de Papers. 
La ICE constituye un grupo de interés asombroso en términos de los recursos de muy distinto tipo a su alcance. No solo posee y administra una herencia histórica y artística de incalculable valor, sino que también agrupa a más de 40.000 instituciones que pueden desglosarse de la siguiente forma ${ }^{12}$ :

- 22.700 parroquias.

- 906 monasterios y congregaciones religiosas.

- 13.000 cofradías, fundaciones y ONGs.

- 235 hospitales y centros de salud (que asisten a 1.237.084 pacientes).

- 876 casas de ancianos y discapacitados (57.653).

- 937 orfanatos (10.835).

- 321 guarderías (10.607).

- 365 centros de educación especial (53.140).

- 144 centros sociales (324.377).

- 305 centros para la defensa de la vida y de la familia (79.868).

- 155 centros de reinserción (45.000).

- 54 centros para la atención a drogadictos y 24 de asistencia a enfermos de sida.

- 5.000 colegios (con 1.741 .697 estudiantes) y 200 universidades.

También es muy relevante la presencia de la ICE en el mundo de los medios de comunicación (cuadro 2).

La COPE (Cadena de Ondas Populares Españolas) está constituida por un conglomerado de empresas mediáticas en el que la CEE posee un 51,05\% de las acciones y la diócesis, un 21,14\%. La CEE tiene un 51,1\% de las acciones

Cuadro 2. Principales grupos de medios de comunicación en Madrid (2005-2006)

\begin{tabular}{lll}
\hline Propietario & Grupo/empresas & Facturación (millones $€$ ) \\
\hline Timón (Polanco) & Prisa + Sogecable (44,5\%) & $2.099,8$ \\
Telefónica & Telefónica de Contenidos & $1.269,1$ \\
SEPI (Estado español) & RTVE + Agencia Efe & 977,5 \\
Ibarra/Bergareche/Echevarria & Vocento + Gestevisión & \\
& Telecinco (13\%) & 915,5 \\
Fernando Ocaña & Tapsa & 215,0 \\
Compañía de María & Fundación SM & 174,0 \\
Rueda Rodríguez & Ediciones Rueda & 156,0 \\
Wisdom (Pérez Dolset) & Lanetro Zed & 135,6 \\
Sánchez Junco & Hola & 119,3 \\
CEE & COPE & $\mathbf{9 0 , 5}$ \\
\hline
\end{tabular}

Fuente: Jones, 2007.

12. http://6865.blogcindario.com/2007/11/04483-la-iglesia-catolica-en-espana-noviembre-de2007-campana-de-comunicacion.html 
de la emisora de radio COPE y posee el 67,1\% de la cadena de TV Popular - en términos comparativos, la emisora de radio tiene un éxito notable, pues es tercera en audiencia (737.000 oyentes diarios) según el último estudio de medios de noviembre de 2009 (Vidal, 2010).

El contraste entre enormes recursos y un "personal limitado" es, sin embargo, igualmente sorprendente. Existen, dentro de la ICE, un total de 19.000 sacerdotes (de los que 9.000 están jubilados) y la edad media de los que están en activo es de 51 años. Además, la Iglesia cuenta únicamente con 1.200 seminaristas (en las dos últimas décadas, este número ha bajado de 2.000 a 1.200 , al tiempo que las vocaciones han descendido alrededor del 30\% desde 1990) (http://www.esglesiaplural.cat/modules.php?name= News\&file=article\&sid=832; www.eldiariomontanes.es). En un estudio financiado por la católica Fundación Santa María, titulado Juventud 2000 y religión, se preguntó a una muestra de jóvenes acerca de la utilidad social de 13 trabajos distintos y la del sacerdocio quedó en la doceava posición, mientras que únicamente el $0,7 \%$ de los entrevistados reconoció la posibilidad de convertirse en sacerdote (www.pastoral-vocacional.org; Fundación Santa María, 2000).

\subsection{Una iglesia con recursos en una sociedad secularizada}

A pesar de la impresionante y continua presencia de la Iglesia en la sociedad española, los españoles han experimentado (como la mayoría de los europeos) un proceso creciente de secularización. La principal diferencia entre ambos grupos es que la secularización ha ocurrido más tarde y a un ritmo más rápido en España que en Europa: «entre 1981 y 1990, el declive de la práctica religiosa ha sido más fuerte que en ningún otro lugar, y lo mismo ha ocurrido con las vocaciones religiosas» (Davie, en Pérez-Agote, 2008: 177). «Más de la mitad de la población católica nunca va a misa —en algo más de dos décadas, casi un $20 \%$ más de católicos ha dejado de asistir a los oficios [y] aquéllos que van todos los domingos no alcanzan un quinto en el 2008, mientras que en 1985 eran más de un cuarto» (Martín y Tsirbas, 2009: 15). Aunque la práctica ha descendido, los rituales católicos siguen siendo importantes: por ejemplo, el porcentaje de matrimonies civiles ha aumentado del 24,18 (1999) al 39,01 (2005), pero las bodas religiosas solo han experimentado un ligero descenso, del 75,5 (1999) al 70,7 (2002) (Ariño, 2008: 239); en el 2002, además, un $78,5 \%$ de los entrevistados declaraba que bautizaría a sus hijos (Pérez-Agote, 2008: 181).

En el 2004, un 26,6\% afirmaba no pertenecer a ninguna religión (frente al 21,7 en el 2002), mientras que un $68,9 \%$ mostraba una identidad católica (el 75,4\% en el 2002) (European Social Survey, 2004). En una escala del 0 (no religioso) al 10 (muy religioso), la media de los españoles se ubica aproximadamente en el medio $(5,3)$. La religión ha perdido relevancia en la vida de las personas (del 6,11 en 1987 — dentro de una puntuación máxima del 10al 5,34 en 2002) y es menos importante que la salud, la familia, el trabajo, los 
Cuadro 3. Aceptación o rechazo hacia la influencia electoral y política de la Iglesia

Hasta qué punto está de acuerdo o no con las siguientes frases (2002)

\begin{tabular}{ccll} 
Estoy de acuerdo & Ni de acuerdo & $\begin{array}{l}\text { No estoy de } \\
\text { acuerdo y estoy }\end{array}$ & $\begin{array}{l}\text { No sabe } \\
\text { y no }\end{array}$ \\
o muy de acuerdo & ni en desacuerdo & muy en desacuerdo & contesta \\
\hline
\end{tabular}

Las autoridades religiosas no deberían intentar influir

en el voto de la gente 82,3 6,5 6,2 4,9

Las autoridades religiosas no deberían intentar influir en las decisiones del gobierno 81,1 7,2 6,5 5,2

Fuente: Santiago, 2008: 212.

amigos y el bienestar económico (solo la política está por debajo de la religión) (Santiago, 2008: 209). Cerca de tres millones de personas (7-8\% de la población) pertenece a iglesias que no son la ICE. Menos del 50\% de los españoles confía en la ICE - un porcentaje que está por debajo de la media europea (Elzo, 2000: 82, 85). Si se compara, sin embargo, la ICE con otras instituciones en términos de confianza (y se suman las categorías «mucha» $\mathrm{y}$ "bastante» confianza), la Iglesia y las organizaciones religiosas se sitúan en la quinta posición de un total de once. En cuanto al poder que se adscribe a la ICE, solo el 9\% considera que tiene demasiado poco (Pérez-Agote y Santiago, 2005: 120). Las encuestas indican, asimismo, que existe un amplio rechazo a que este (percibido como amplio) poder sea ejercido en la esfera política (cuadro 3).

Es también relevante que las encuestas de opinión muestren una gran tolerancia hacia los temas que recogen las PAS. En una de las últimas del CIS (no 2752, 2008), el 60\%, el 62,1\% y el 51,7\% de los encuestados se mostraba en contra de la postura de la ICE en los temas del aborto, el matrimonio homosexual y la adopción de niños por parte de parejas gay, respectivamente. La existencia de una mayoría de opiniones «liberales» en asuntos morales es extraordinaria si se tiene en cuenta que un $95,1 \%$ de los españoles mayor de dieciocho años afirmó, en el 2002, que había tenido una educación católica (Santiago, 2008: 213). La aprobación frente al rechazo de las PAS muestra «divisiones religiosas [que] se forjan en torno a la aceptación o al rechazo de la posición de la Iglesia» (Calvo, Martínez y Montero, 2010: 9).

\section{Las alianzas de la Iglesia católica en tiempos de crisis}

La ICE se ha decidido a adoptar una estrategia política de confrontación porque han concurrido cuatro circunstancias distintas:

- La existencia de un mercado religioso cuasi monopolista que facilita el enmarcado (framing) de las reivindicaciones de la Iglesia en términos de 
«la institución que representa a la gran mayoría de los españoles», que son católicos de nacimiento o se definen como tales.

- La existencia de percepción de amenaza (tiempos de crisis) que deriva de la aprobación de ciertas PAS, en particular, y del programa laicista de Zapatero, en general.

- La existencia de importantes alianzas con determinados grupos sociales.

- La capacidad para encontrar aliados políticos en la lucha contra las PAS ${ }^{13}$.

La opción por una estrategia política de adversario no debe ser vista como el único lógico curso de actuación para las IC. En otros países europeos, como Bélgica, la IC, aunque se ha opuesto a reformas políticas similares a las aprobadas en España, no ha elegido la estrategia de la movilización conflictiva: sus aliados políticos (los cristiano-demócratas) han votado contra estos proyectos legislativos en el Parlamento, pero tanto el partido, como la propia Iglesia, se han abstenido de activar políticamente a sus bases sociales (Botterman y Hooghe, 2009). Otro ejemplo sería el de la sociedad portuguesa, que, a pesar de ser más religiosa (católica) que la española (un 86\% frente a un 75\% declara pertenecer a alguna iglesia), no ha experimentado el conflicto religioso que la ICE y otros actores han promovido en España: la «consolidación de un sistema de partidos dominado por dos partidos de centro muy parecidos entre sí en un gran número de cuestiones ideológicas» no ofrece a las elites políticas los incentivos necesarios para jugar la carta religiosa en Portugal. En España, por el contrario, no solo la ICE sino también «las condiciones políticas (centradas en las preferencias y estrategias de las elites) e institucionales (un sistema de partidos cuyos integrantes pueden recurrir a diversos espacios de identificación) [han contribuido a promover] el eventual fortalecimiento del voto religioso» (Montero, Calvo y Martínez, 2008: 21).

\subsection{Las alianzas sociales: los grupos laicos de inspiración cristiana}

De forma relativamente reciente, «han aparecido movimientos sociales que son religiosos por naturaleza o retan en nombre de la religión la legitimidad y la autonomía de las esferas seculares primarias, el estado y la economía de mercado» (Casanova, 1994: 5). Este tipo de movimientos (en concreto, asociaciones laicas católicas y/o de inspiración cristiana que, en muchos casos, se autodefinen como aconfesionales) han tomado la iniciativa a la hora de protagonizar una intensa movilización en España para protestar contra las PAS. Existe una clara sintonía entre estas asociaciones y la ICE a la hora de defender un modelo de sociedad en el que los valores religiosos tengan una presen-

13. Para que se produzcan estas alianzas, las PAS deben, evidentemente, englobar temas (issues) cruciales no solo para la Iglesia, sino también para sectores sociales significativos, en el sentido de que los grupos muestren interés en los mismos (saliency) y se encuentren divididos en cuanto a cómo afrontarlos (skewness), mientras que los partidos deben ofrecer alternativas distintas con relación a los mismos temas (differentiation) (Norris, 1997: 80). 
cia pública asegurada (dentro de los mismos, el catolicismo mantiene una relevancia indiscutible) y en el que el estado se abstenga de intervenir en cuestiones éticas y morales. Estos aliados laicos, muchos de ellos fundados en las dos últimas décadas, están más cerca de una visión conservadora dentro de la Iglesia que ha ganado peso con el actual presidente de la CEE, cardenal Rouco, que ciertos sectores del clero o grupos religiosos influidos por el carácter reformista del Concilio Vaticano II.

Aunque existen indudables diferencias entre estos grupos cristianos, comparten también ciertos rasgos: la participación de jóvenes suele ser la regla o, al menos, se promueve activamente su implicación; su naturaleza es laica (aunque en algunos casos contados se han creado unidades dirigidas por sacerdotes); generalmente, exhiben una orientación espiritual ética, y no social, y podrían ser caracterizados como no inclusivos y tradicionales en cuanto a su adscripción a un código ético estricto basado en principios universales absolutos; asimismo, tienden a preferir estrategias de movilización en el espacio público (grandes manifestaciones) frente a otras de tipo más convencional vinculadas al lobbying. Es igualmente importante que coincidan con los dictados de la CEE: estos grupos sociales refuerzan las campañas de la ICE de manera distinta (dándoles publicidad en sus páginas web, apoyando los objetivos de la Iglesia en ruedas de prensa y actos de protesta, etc.) y sus líderes se han manifestado junto con figuras religiosas (y también políticas) en contra de las PAS en numerosas ocasiones. La coincidencia con los planteamientos de la CEE podría ser explicada, entre otras razones, por la probabilidad de que la gente que participa en estos grupos sea la misma que muestra una más alta asistencia a los oficios ${ }^{14}$ : puesto que «ir a misa» en España es una práctica que ha ido decayendo en las últimas décadas, los que aun siguen haciéndolo se encuentran con toda probabilidad más expuestos al discurso oficial de la jerarquía de la Iglesia y se comportan, por lo tanto, como los seguidores más fieles de la estrategia de confrontación política escogida por la ICE. Asimismo, los estudios electorales muestran cómo, desde 1996, los votantes con una mayor frecuencia de práctica religiosa se han ido desplazando hacia la derecha y votan actualmente al PP (Calvo, 2009). Finalmente, es interesante mencionar también que algunos de estos grupos han recibido reconocimiento jurídico especial por parte del Vaticano ${ }^{15}$ y que responden en muchos casos al intento, iniciado en 1978 por el Papa Juan Pablo II y seguido en la actualidad por Benedicto XVI, de aminorar la secularización en el mundo occidental.

14. «La participación religiosa (medida como frecuencia de asistencia a los servicios religiosos) se relaciona de forma positiva con la pertenencia a organizaciones religiosas» (Norris e Inglehart, 2004: 194).

15. En el Congreso Internacional de Movimientos Eclesiásticos, celebrado en Roma en 1998, de un total de 56 grupos, a siete se les concedió un reconocimiento especial debido a su «representación universal». Dentro de estos grupos estaban Camino Neocatecumenal (creado en España) y otros dos de origen italiano: Obra de María y Comunión y Liberación. Es necesario recordar que el Opus Dei disfruta de una relación directa con el Vaticano. 
Las diferencias dentro de los grupos laicos católicos y/o de inspiración cristiana se relacionan con tres factores distintos: 1) momento de creación; 2) existencia de una implícita división interna del trabajo, y 3 ) adopción de distintas estrategias y repertorios.

1) En términos de tiempos, puede distinguirse entre los grupos recientemente creados y los de más larga trayectoria: a la primera categoría pertenecen aquéllos que han adquirido relevancia al calor del revuelo provocado por las PAS (el Foro Español de la Familia -el Foro-, creado en 1999, y Hazte Oír — HO_, del 2001, por ejemplo) ${ }^{16}$, mientras que la segunda recogería organizaciones más antiguas como la Concapa (1929) y Camino Neocatecumenal (1964).

2) En cuanto a la "especialización temática», la distinción sería entre grupos pro vida (HO, Derecho a la Vida, etc.), pro familia (Foro, etc.), orientados al ámbito educativo (Concapa, etc.), y de tipo pastoral (Camino Neocatecumenal, Obra de María, Opus Dei, Comunión y Liberación, etc.). Esta distinción no impide que muchos de ellos participen conjuntamente en las mismas campañas: Concapa ha asistido, por ejemplo, a manifestaciones pro vida y en contra del matrimonio homosexual aunque su interés se sitúe en el campo de la educación; el Foro, por otro lado, se ha mostrado activo en las protestas contra las reformas educativas y el aborto.

3) En relación con las diferencias estratégicas, los grupos podrían ser clasificados a lo largo de un continuo radical versus convencional. La rivalidad entre el Foro y $\mathrm{HO}$ es un ejemplo de este tipo de diferencia y es la que probablemente mejor explica la decisión del segundo de abandonar el Foro en octubre del 2009. Aunque oficialmente se anunció que esta decisión era el resultado de discrepancias organizativas — se acusó al Foro de imponer ciertas formas de trabajo sobre sus organizaciones miembro al tiempo que no respetaba su autonomía-, el contraste entre el estilo más radical y abiertamente crítico de $\mathrm{HO}$ y el más convencional del Foro puede ser una razón más relevante a la hora de entender fricciones internas. HO, un grupo compuesto por gente joven cuyo presidente fomenta el uso de las nuevas tecnologías de la información como instrumentos para la acción política de inspiración cristiana, no se inhibe a la hora de criticar abiertamente el liderazgo del PP (Rajoy es su principal blanco) debido a su supuestamente dubitativa postura en relación con el aborto; sin embargo el Foro, cuyo principal representante fue Secretario de Estado con el gobierno del PP, adopta una perspectiva más cauta y menos agresiva. Es también interesante que el repertorio del Foro sea más amplio que el de $\mathrm{HO}$, en el sentido de combinar tanto técnicas convencionales (iniciativas legislativas populares,

16. Benigno Blanco, presidente del Foro, ha reconocido que su organización «adquirió un nuevo ímpetu tras la llegada al poder del PSOE». 
Cuadro 4. Número de miembros de los grupos católicos y/o de inspiración cristiana

\begin{tabular}{ll}
\hline Nombre del grupo & Miembros y apoyos \\
\hline Concapa & 3 millones de padres. \\
Foro Español de la Familia & $\begin{array}{l}\text { Más de } 5.000 \text { asociaciones y } 4 \text { millones de } \\
\text { miembros. }\end{array}$ \\
Hazte Oír & $\begin{array}{l}100 \text { voluntarios, } 4 \text { empleados y más de } 15.000 \\
\text { suscripciones en su página web. } \\
\text { Camino Neocatecumenal }\end{array}$ \\
Obra de María (creado en 1943) & 4.000 miembros. \\
Opus Dei (1928) & 30.000 miembros. \\
Comunión y Liberación (1954) & 3.000 miembros.
\end{tabular}

recurso a los tribunales, etc. $)^{17}$ como otras de tipo más contencioso, al tiempo que confía menos en los instrumentos «virtuales» on line.

Todas estas diferencias explican que no se pueda hablar de forma apresurada acerca de la completa unidad y cohesión de un denominado «bloque católico», tal y como han hecho algunos autores ${ }^{18}$. Según estos grupos cristianos, el número de miembros puede ser dividido como muestra el cuadro 4 .

El total de miembros (si se incluye los Legionarios de Cristo, fundados en 1941) sería aproximadamente de 4.500 .000 a 5.000 .000 (estimación propia basada en Sánchez-Vallejo, 2009 —www.redescristianas.net — y otras páginas web). La existencia de afiliación solapada (overlapping membership) es, sin embargo, frecuente (Concapa pertenece al Foro, por ejemplo, y HO afirma tener miembros del Opus Dei y de los Legionarios de Cristo en sus filas) y, por lo tanto, no es fácil alcanzar una cifra exacta de miembros.

\subsection{Las alianzas políticas. ¿Existen partidos cristiano-demócratas en España?}

Aunque la ICE no ha apoyado oficialmente a ningún partido en democracia, ya en 1977 la CEE dio a conocer un documento titulado La responsabilidad moral del voto, que fue interpretado como un ataque a los partidos de izquierda. La justificación de esta «intromisión política» se hizo en los siguientes tér-

17. El Foro promovió una iniciativa popular legislativa contra el matrimonio gay que llegó al Parlamento en 2007 y fue ulteriormente rechazada. Asimismo, y en conjunción con otros grupos, ha recurrido a los tribunales en su lucha contra la asignatura educación para la ciudadanía.

18. «El bloque católico defiende un proyecto unitario, designado principalmente por la jerarquía, y compuesto por cuatro sectores: los intelectuales orgánicos que pertenecen a la jerarquía [...]; los organizadores de las masas católicas (Concapa, Camino Neocatecumenal...); los medios de comunicación (COPE, $A b c$, La Razón...); y los partidos políticos de inspiración católica» (Díaz-Salazar, 2008b: 141). 
minos: «la Iglesia no puede mostrarse indiferente ante el destino de nuestro pueblo [...] y no puede mostrarse neutral cuando se encuentra ante posibles amenazas a los valores éticos o los derechos humanos» (www.conferenciaepiscopal.es). Partidos como la UCD y Coalición Democrática (CD) aprovecharon esta oportunidad para presentarse como formaciones demócrata-cristianas: la primera aludió a «la protección de la familia» y a su «identidad humanista cristiana», mientras que CD utilizaba «los conceptos cristianos de la familia y del derecho a la vida» como eslóganes políticos (se puede, asimismo, atribuir una visión similar a AP, definida por uno de sus líderes como «nuestro partido no es confesional, aunque defiende la gran tradición cristiana de España»). En la última retransmisión televisiva de la campaña, Adolfo Suárez presentó a los electores una elección entre «la perspectiva de humanismo cristiano que inspiraba a la UCD y el materialismo de los partidos marxistas, socialistas y comunistas» (Gunther et al., 1988: 222-224).

La ausencia de apoyo explícito a ningún partido durante la transición democrática puede ser interpretada de diferentes formas:

- Es razonable hipotetizar que la ICE no necesitó hacer públicas sus preferencias políticas porque podía esperar un trato favorable por parte del partido que contaba con mayores posibilidades de victoria: la UCD, un partido centrista que albergaba muy distintas «familias políticas», incluyendo a los demócrata-cristianos ${ }^{19}$.

- La ICE, consciente de la extendida percepción social acerca de su inequívoco apoyo a la dictadura franquista hasta bien entrados los años sesenta, se mostró remisa a la hora de "apostar» explícitamente por algún partido político. Lo mismo podría haber sucedido en el caso de los partidos, recelosos ante las consecuencias electorales no intencionales de un apoyo evidente por parte de la Iglesia.

- A diferencia de la Segunda República, la ICE no percibió la llegada de la democracia como una amenaza (el liderazgo eclesiástico, encarnado en el cardenal Tarancón, se había preparado gradualmente para el cambio político, de la misma forma que la oposición, especialmente el Partido Comunista, que quería evitar la confrontación con la Iglesia a toda costa) (Linz, 1993: 33-4).

- La existencia de activistas católicos en las filas de los grupos de la oposición (tanto en el PSOE y el PCE, como en los sindicatos CCOO y UGT)

19. La aprobación del Estatuto Educativo (1980) y de la ley del divorcio (1981) generó tensión dentro de la UCD entre los sectores más próximos a la ICE y aquéllos más «laicos». En 1981, cuando la crisis interna de UCD era evidente, Alzaga lideró una plataforma DC. Esta iniciativa fue el resultado de las fricciones entre los cristianodemócratas y los socialdemócratas, cuyo principal líder, Fernández Ordónez, había promovido la ley del divorcio. Los primeros abandonaron la UCD en 1982 y formaron el Partido Demócrata Popular, mientras que otras figuras también cristianas, como Herrero de Miñón, se unieron a AP (Huneeus, 1985: 352-7). Según Soto, la UCD mantuvo una considerable autonomía frente a la Iglesia (Pérez-Agote, 2008: 119). 
constituía una clara prueba del inexistente consenso partidista dentro de la ICE.

- El clima posterior al Concilio Vaticano Segundo, que había transformado la Iglesia en una institución centrada en la sociedad y sin vínculos explícitos con formaciones políticas ${ }^{20}$, desalentaba el apoyo oficial de la ICE a los partidos.

Aunque la ICE no apoyara ningún partido, tenía distintas formaciones a su alcance y, finalmente, decidió favorecer a la UCD de manera no oficial en 1977. Miembros de AP protestaron agriamente por esta decisión y una alta figura del partido recalcó que la Iglesia se comportaba de manera «inexplicablemente beligerante a favor de la UCD». El «sesgo» de la Iglesia se trasladó a numerosos editoriales del diario cristiano $Y a$, los cuales promovían el voto útil por la UCD al tiempo que caracterizaban como perdidos los votos por CD (Gunther et al., 1988: 229). «El triunfo electoral de la UCD [en 1977] implicó [...] el fracaso de la Democracia Cristiana en España» (Huneeus, 1985:176) y refutó la extendida predicción académica que anticipaba un sistema de partidos caracterizado por la presencia de una fuerte formación de inspiración demócrata-cristiana (DC). Entre otras razones, «la fragmentación de los partidos DC durante el período franquista, [la existencia de] diferencias personales entre sus principales líderes y los errores políticos cometidos durante los momentos clave de cambio de régimen» explican este fracaso (Huneeus, 1985: 184). Tras las elecciones de 1977, en las que ninguno de los partidos DC nacionales obtuvo ningún tipo de representación, algunos de sus líderes se unieron a la UCD y ocuparon carteras importantes durante los dos gobiernos centristas (1977-1979 y 1979-1982). Solo un partido de ámbito nacional que también proclamaba su inspiración cristiana, Alianza Popular (refundado como PP en 1989), sobrevivió a la debacle DC. Tras perder UCD el poder en 1982, la ICE se encontró privada de un importante aliado político.

\subsubsection{El aumento de la confrontación política de inspiración religiosa desde los años noventa}

«Durante los años ochenta, los líderes políticos y sociales renunciaron a incorporar los conflictos religiosos a la agenda política y a movilizar a los votantes bajo criterios religiosos o antirreligiosos en los distintos ámbitos de la competición electoral. Pero, desde hace al menos quince años, estos criterios están interviniendo en el debate político en la medida en que las elites desean obtener beneficios electorales apelando a las identidades religiosas de los votantes [...] el

20. De los cuatro documentos principales que dimanan del Concilio Vaticano Segundo -Dignitatis Humanae, Gaudium et Spes, Lumen Gentium y Christus Dominus-, el más relevante desde el punto de vista político es el primero que afirma «la cuestionabilidad de cualquier tipo de partido católico o movimiento político oficialmente patrocinado por las IC» (Casanova, 1994: 72). 
número total de votantes religiosos ha ido descendiendo con el tiempo [...] es más fácil encontrar votantes que emplean la religiosidad para fundamentar su apoyo a los partidos conservadores que la situación contraria [esto es así porque desde] mediados de los noventa el voto religioso conoció una notable recuperación, ligada precisamente a una cierta clarificación de los perfiles religiosos de los principales partidos españoles» (Calvo, Martínez y Montero, 2010: 4, 8, 10).

Actualmente, los principales partidos de inspiración cristiana son el PP, en el ámbito nacional, y el PNV y la UDC (socio de coalición de CDC), en el regional. Sin embargo, no todos se definen de la misma forma o reconocen explícitamente sus raíces cristianas: el PP resalta ser una «formación política centrista» que se adhiere a la tradición del liberalismo español, el PNV recoge su naturaleza «humanista y aconfesional» y solo UDC incorpora de forma inequívoca su «inspiración demócrata-cristiana» (www.pp.es; www.eajpnv.eu; www.unio.org). La afiliación transnacional de estos partidos es también diferente: el PP y la UDC pertenecen al Partido Popular Europeo, mientras que el PNV y Convergència se adscriben a la Alianza de Liberales y Demócratas de Europa. En la lucha contra las PAS promovidas por el PSOE, la ICE ha encontrado un apoyo desigual en el PP, el PNV y la UDC, así como en otros partidos menores. De forma simplificada, la alianza entre la Iglesia y determinadas fuerzas políticas se ha desarrollado a lo largo de tres etapas distintas:

La ICE expresa sus opiniones antes de las elecciones y previene al electorado católico en cuanto a su posible voto a favor de partidos cuyos programas irían en contra de los valores cristianos - el ultimo ejemplo es el texto dado a conocer antes de los comicios del año $2008^{21}$. Al realizar este ejercicio, la Iglesia favorece implícitamente (sin apoyar oficialmente) a los partidos DC.

Si los resultados electorales son contrarios a los intereses de la ICE, ésta recurre a aquellos partidos próximos a sus tesis a pesar de que no haya vínculos formales con los mismos. Los debates y las votaciones parlamentarios sobre las PAS constituyen una clara señal acerca de qué partidos son afines a la Iglesia.

Si el proceso parlamentario resulta contrario a los objetivos de la ICE y las PAS son finalmente aprobadas, la Iglesia puede recurrir a aquellas fuerzas políticas que votaron en contra de las mismas (la presión política y las estrategias de movilización pueden haber tenido lugar antes de que las PAS salieran adelante).

21. En el texto, se recoge: «si bien es verdad que los católicos pueden apoyar partidos diferentes [...] también es cierto que no todos los programas son igualmente compatibles con la fe y las exigencias de la vida cristiana [...] no se debe confundir la condición de aconfesionalidad o laicidad del estado con la desvinculación moral y la exención de obligaciones morales objetivas [...] no pretendemos que los gobernantes se sometan a los criterios de la moral católica, pero sí que se atengan al denominador común de la moral fundada en la recta razón y en la experiencia histórica de cada pueblo». De forma similar, el obispo de Tarazona expresaba que no todos los partidos son lo mismo y que la ICE «acepta los resultados de las elecciones por respeto al sistema democrático [...] pero los cristianos [deben] votar por aquellos partidos que tienen programas coherentes con la fe cristiana». 


\section{Estrategias de movilización contra las políticas altamente sensibles}

Para defender los objetivos pro familia y pro vida, la ICE ha escogido una estrategia política conflictiva que se refleja en un abanico diverso de actuaciones: desde la presión política y el lobby, la organización de conferencias de prensa y la publicación de comunicados, hasta el apoyo a las manifestaciones organizadas por los grupos laicos católicos y/o de inspiración cristiana.

El repertorio político de la ICE se ha visto, pues, ampliado: cuando las estrategias convencionales de presión fracasan, la Iglesia puede contar con sus aliados sociales, en primer lugar, y políticos, de manera subsidiaria, para sacar a la gente a la calle. La movilización de sus bases no impide que, al mismo tiempo, se sigan utilizando actuaciones no contenciosas, como, por ejemplo, el recurso a los tribunales por parte de grupos afines. Las expresiones públicas de descontento han adquirido en ciertos casos un tono inusualmente radical, como cuando el arzobispo de Valencia, García Gasco, afirmó, antes de las elecciones del 2008, que las medidas del PSOE «conducían a la disolución de la democracia». Esa y otras declaraciones, como la de la CEE, que señalaba que la agenda socialista perseguía «excluir a los católicos de la vida pública [así como] acelerar la aplicación del laicismo y del relativismo moral como la única mentalidad compatible con la democracia», o la de su portavoz, que acusó a los socialistas de promover políticas que «degeneran sin remedio en dictadura, discriminación y desorden», al tiempo que crean una sociedad «desvertebrada, literalmente desorientada, fácil víctima de la manipulación, de la corrupción y del autoritarismo» (http://ecodiario.eleconomista.es; www.conferenciaepiscopal.es; El Pais, 31-1-2008), han favorecido que ciertos líderes del PSOE describan a la ICE como un actor al servicio de los intereses electorales del $\mathrm{PP}^{22}$.

Frente al radicalismo verbal de ciertas figuras eclesiásticas, la Iglesia ha mostrado una gran cautela a la hora de ejercer el protagonismo en las acciones callejeras. De hecho, es importante resaltar que la mayoría de estas actuaciones no han sido directamente organizadas por la Iglesia, sino por los grupos laicos católicos y/o de inspiración cristiana, con el apoyo no siempre oficial de determinados partidos. La jerarquía religiosa ha participado de forma visible en alguna de estas manifestaciones (así se podrían considerar las dos misas públicas, del 30 de diciembre de 2007 y del 30 de diciembre de 2009, a favor de la familia cristiana y en contra del matrimonio homosexual), mientras que en otras ocasiones se ha anunciado que los obispos no se unirían a las mismas (tal y como el cardenal Rouco Varela declaró en relación con la protesta en contra del aborto del 17 de octubre del 2009). En esta misma línea de no exposi-

22. No hay que olvidar, además, que la ICE ha criticado también «el reconocimiento de una organización terrorista como interlocutor político», en alusión al fallido intento del gobierno de Zapatero por negociar una tregua con ETA, una decisión que fue duramente criticada por el PP. Asimismo, la rebelión de la Iglesia contra la asignatura educación para la ciudadanía, aprobada por el PSOE en el año 2007, ha encontrado un amplio respaldo en los gobiernos regionales de Madrid y Valencia, en manos del PP. 
ción pública de vínculos formales entre la Iglesia y sus aliados sociales y políticos, los grupos laicos de inspiración cristiana han puesto el énfasis repetidamente en que las grandes movilizaciones son «manifestaciones civiles» y han asegurado que en las mismas no se admiten «adhesiones de partidos políticos o confesiones religiosas». A pesar de ello, es indudable que la ICE, a través de sus comunicados y de los sermones en las iglesias, así como determinados partidos (PP, UDC y también UPN, de forma más significativa), mediante la promoción de la participación a título individual o colectivo (el envío de SMS desde Nuevas Generaciones a sus miembros, por ejemplo), han contribuido estratégicamente a la organización de tales eventos.

\section{Conclusiones}

Este trabajo analiza la ICE como un grupo de interés que persigue mantener y/o aumentar su influencia política en democracia mediante la adopción de decisiones racionalmente calculadas que afectan a su statu quo y a sus objetivos declarados. Para ello, la Iglesia se ve "forzada» a forjar alianzas con determinados grupos sociales y partidos políticos. La estrategia política de la Iglesia puede, sin embargo, adoptar un perfil bajo o alto. Éste último se traduce generalmente en el desempeño de un activo papel de adversario político. Ésta ha sido la estrategia elegida por la ICE con respecto a dos reformas políticas promovidas por el gobierno socialista de Zapatero: la que ha conducido a la aprobación del matrimonio para personas del mismo sexo y la que ha ampliado la despenalización del aborto. La pregunta que orienta el presente estudio es por qué la ICE se ha implicado tan intensamente en esta lucha política, plasmada en el desarrollo de campañas y en la movilización social contra estas reformas, cuando otras iglesias católicas en distintos países europeos se han abstenido de ejercer un protagonismo político similar. La explicación pone el énfasis en el lado de la oferta, es decir, en el tipo de Iglesia y de liderazgo religioso existente en España. Las causas del activismo político de inspiración religiosa son, pues, endógenas: una iglesia que cuenta con importantísimos recursos de todo tipo y que funciona en un mercado religioso cuasi monopolista, el cual facilita que la ICE se presente como «la institución que representa a la gran mayoría de los españoles»; su situación privilegiada en el contexto de un estado aconfesional; la percepción de grave amenaza que deriva de la aprobación de ciertas «políticas altamente sensibles» acerca de las cuales, además, ciertos sectores sociales exhiben una alta intensidad de preferencias, y la existencia de importantes aliados sociales (o grupos de inspiración cristiana) y políticos (principalmente el PP y UDC) contrarios a las reformas socialistas. Para defender los objetivos pro vida y pro familia, la ICE ha escogido una estrategia política conflictiva que abarca desde la presión política y el lobby, la organización de conferencias de prensa y la publicación de comunicados, hasta el apoyo (y, en ocasiones, promoción directa) a manifestaciones organizadas primordialmente por grupos sociales y, subsidiariamente, por partidos. 


\section{Referencias bibliográficas}

Aldridge, Alan (2000). Religion in the contemporary world. Cambridge: Polity Press. Allingham, Michael (2002). A very short introduction: Choice theory. Oxford: Oxford University Press.

Anderson, John (2003). "Catholicism and democratic consolidation in Spain and Poland». West European Politics, enero, 1.

AriÑo Villaroya, Antonio (2008). «Religión eclesiástica y religión común en España». En: Pérez-Agote, A. y Santiago, J. (eds.). Religión y política en la sociedad actual. Madrid: UCM y CIS.

BERGER, Peter L. (1999). The desecularization of the world: Resurgent religion and world politics. Washington: Ethics and Public Policy Center.

BERRY, Jeffrey M. (1997). The interest group society. Nueva York: Longman.

BotTERman, Sarah y Hooghe, Marc (2009). The christian democratic vote and religious belonging. Comunicación presentada en la ECPR General Conference. Postdam, 10-13 de septiembre.

Calvo, Kerman (2009). "Calidad de la democracia: Las leyes de derechos civiles y la reforma de la política». En: BosCo, Anna y SÁnCHEZ-CuEnCA, Ignacio (eds.). La España de Zapatero: Años de Cambio, 2004-2008. Madrid: Fundación Pablo Iglesias, p. 205-227.

Calvo, Kerman; Martínez, Álvaro y MonTero, José Ramón (2010). Devotos y votantes: El peso del factor religioso en las elecciones generales (mimeo).

Casanova, José (1994). Public religions in the modern world. Chicago, Londres: The University of Chicago Press.

DíAZ-SALAZAR, Rafael (2006). El factor católico en la politica española. Del nacionalcatolicismo al laicismo. Madrid: PPC.

- (2008a). «La cohesión social y las formas públicas de la religión en las sociedades contemporáneas». En: BERICAT, Eduardo (coord.). El fenómeno religioso: Presencia de la religión y de la religiosidad en las sociedades avanzadas. Sevilla: Fundación Centro de Estudios Andaluces.

- (2008b). «Institución religiosa y democracia en España». En: PÉREZ-Agote, A. y SANTIAGO, J. (eds.). Religión y politica en la sociedad actual. Madrid: UCM y CIS.

Elzo, Javier (2000). Jóvenes 2000 y religión. Madrid: Fundación Santa María.

- (2008). «La evolución socio-religiosa en España en los últimos 30 años: Una aproximación empírica». En: BERICAT, Eduardo (coord.). El fenómeno religioso: Presencia de la religión y de la religiosidad en las sociedades avanzadas. Sevilla: Fundación Centro de Estudios Andaluces.

ESTEBAN, Valeriano (2008). «La secularización en entredicho: La revisión de un debate clásico de la sociología». En: BERICAT, Eduardo (coord.). El fenómeno religioso: Presencia de la religión y de la religiosidad en las sociedades avanzadas. Sevilla: Fundación Centro de Estudios Andaluces.

EUROPEAN SOCIAL SURVEY (2004). http//ess.nsd.uib.no.

GUNTHER, RicHARD; SANI, Giacomo y SHABAD, Goldie (1988). Spain after Franco: The making of a competitive party system. California: University of California Press.

GurrutXaga ABAD, Ander (2008). "La institución lobby: La religión en la política». En: PÉreZ-Agote, A. y SANTiAgo, J. (eds.). Religión y politica en la sociedad actual. Madrid: UCM y CIS.

Hirshman, Albert O. (1979). Exit, Voice and Loyalty. Harvard: Harvard University Press. 
Hirshman, Albert O. (1970). Exit, voice and royalty. Harvard University Press: Cambridge, Massachussets.

Huneeus, Carlos (1985). La Unión de Centro Democrático y la transición a la democracia en España. Madrid: CIS.

JONES, Daniel E. (2007). "Grupos mediáticos y culturales en España». ZER, 22. [www.ehu.es/zer/zer22/ZER\%2022_jones.pdf]

Kuru, Ahmet T. (2007). "Historical conditions, ideological struggles and state policies toward religion». World Politics, 59, 4.

LENOIR, Frédéric (2003). Las metamorfosis de Dios: La nueva espiritualidad occidental. Madrid: Alianza Editorial.

LinZ, Juan José (1993). «Religión y política en España». En: DíAZ-SALAZAR, Rafael y GINER, Salvador (eds.). Religión y sociedad en España. Madrid: CIS.

LIPSET, Seymour M. y RoKKAN, Stein (1967). Party systems and voter alignments. Nueva York: The Free Press.

LuCKMAnn, Thomas (1973). La religión invisible. Salamanca: Sígueme.

- (2008). «Reflexiones sobre religión y moralidad». En: BERICAT, Eduardo (coord.). El fenómeno religioso: Presencia de la religión y de la religiosidad en las sociedades avanzadas. Sevilla: Fundación Centro de Estudios Andaluces.

LlamaZARES, Dionisio (2008). «Confesionalidad y laicidad en la Constitución Española de 1978». En: Pérez-Agote, A. y Santiago, J. (eds.). Religión y politica en la sociedad actual. Madrid: UCM y CIS.

Minkenberg, Michael (2003). "The policy impact of church-state relations: Family policy and abortion in Britain, France, and Germany». West European Politics, enero, 1, 2003.

Montero, José Ramón; Calvo, Kerman y MartíneZ, Álvaro (2008). «El voto religioso en España y Portugal». Revista Internacional de Sociología, LXVI (51), 19-54.

MotA, Fabiola (1999). "La realidad asociativa en España». En: SuBIRATS, Joan (ed.). ¿Existe sociedad civil en España? Madrid: Estudios de la Fundación Encuentro.

NORRIS, Pippa (1997). Electoral change since 1945. Cambridge: Blackwell.

Norris, Pipa e IngleHART, Ronald (2004). Sacred and secular: Religion and politics worldwide. Nueva York: Cambridge University Press.

MARTÍn, Irene y TSIRBAS, Yannis (2009). «The church, moral issues and socialist governments in Greece and Spain». Comunicación presentada en ECPR General Conference. Postdam 10-13 de septiembre.

PÉREZ-Agote, Alfonso y SANTIAgo GARCÍA, José A. (2005). La situación de la religión en España a principios del siglo XXI. Madrid: CIS. Opiniones y Actitudes; 49.

PÉREZ-AGOTE, Alfonso (2008). «Altar y trono: Sociología histórica de las relaciones Iglesia-Estado en España». En: Pérez-Agote, A. y Santiago, J. (eds.). Religión y politica en la sociedad actual. Madrid: UCM y CIS.

- (2008). «La secularización de los españoles». En: Pérez-Agote, A. y Santiago, J. (eds.). Religión y politica en la sociedad actual. Madrid: UCM y CIS.

REQUENA, Miguel (2005). «Religión y sociedad: la secularización de la sociedad española». En: GonZÁleZ, Juan Jesús y Requena, Miguel (eds.). Tres décadas de cambio social en España. Madrid: Alianza.

SánCheZ-Vallejo, M.A. (2009). Los nuevos ejércitos del Papa en España. [www.redescristianas.et]

SANTIAGO GARCíA, José A. (2008). «Dimensión consecuencial y estructura social de la vida religiosa en España». En: Pérez-Agote, A. y SANTiAgO, J. (eds.). Religión y politica en la sociedad actual. Madrid: UCM y CIS. 
Stadelmann-STEFFen, Isabelle y TRAunmüller, Richard (2009). «Religion and public policy revisited: The relationship between religion and family policy making in the OECD countries». Artículo presentado en el panel Religion and Politics in the $21^{\text {st }}$ Century. Postdam: ECPR.

VIDAL BOnIfAZ, Francisco (2010). «Burillo y los medios católicos». En: La rueda de la fortuna. 17 de marzo de 2010. Bitácora. [ruedadelafortuna.wordpress.com] Warner, Carolyn M. (2000). Confessions of an interest group. Princeton, New Jersey: Princeton University Press.

\section{Páginas web}

http://conferenciaepiscopal.es.

www.hazteoir.org.

www.cis.es.

www.forofamilia.org.

www.pp.es.

www.eaj-pnv.eu.

www.unio.org.

http://www.esglesiaplural.cat/modules.php? name=News\&file=article\&sid=832.

http://6865.blogcindario.com/2007/11/04483-la-iglesia-catolica-en-espana-noviembrede-2007-campana-de-comunicacion.html.

www.eldiariomontanes.es.

http://ecodiario.eleconomista.es.

www.pastoral-vocacional.org. 